\title{
Aminolysis of $N$-Acyl Derivatives of Bicyclic Oxalactams
}

\author{
Kazuhiko Hashimoto, Hiroshi Sumitomo, and Atsuko Washio \\ Faculty of Agriculture, Nagoya University, Furo-cho, Cikusa-ku, \\ Nagoya 464-01, Japan
}

(Received February 22, 1988)

\begin{abstract}
The aminolysis of $N$-acyllactams with $n$-butylamine was carried out in $N, N$ dimethylformamide at $25^{\circ} \mathrm{C}$. The amine reacted with both of exo- and endocyclic carbonyl groups in the $N$-benzoyl derivatives of bicyclic oxalactams, such as 8-oxa-6-azabicyclo[3.2.1]octan-7-one (1) and the 4(e)-bromo-substituted analogue. In contrast, only the exocyclic carbonyl group in the monocyclic $N$-benzoyllactams, $N$-benzoyl-2-pyrrolidone and $N$-benzoyl- $\varepsilon$-caprolactam, reacted under the same conditions. These results reflect high reactivity of the bicyclic oxalactams in the base-catalyzed ring-opening polymerization. The present aminolysis was kinetically analyzed in order to estimate the reactivity of $\mathrm{N}$-acyllactams more quantitatively.
\end{abstract}

KEY WORDS Bicyclic Oxalactam / 2-Pyrrolidone / $\varepsilon$-Caprolactam / Aminolysis / $n$-Butylamine / Acyllactam / Ring Opening / Reactivity /

$\mathrm{N}$-Acyllactams in general are known to accelerate the initiation in the anionic polymerization of lactams. The growable end groups in the polymerization are also acyllactamtypes. ${ }^{1,2)}$ That is the reason why the reactivity of acyllactams should be estimated in order to understand the anionic polymerization of lactams. ${ }^{3-7}$

Bar-Zakay et al. ${ }^{4,5}$ determined directly the rate constants in the reaction of $\mathrm{N}$-acetyl-2pyrrolidone and $N$-acetyl- $\varepsilon$-caprolactam with lactamate magnesium bromides and found that the exo-carbonyl groups in preference to the endo-carbonyl ones reacted with the lactamates. Other easy approaches to estimate the reactivity of the $\mathrm{N}$-acyllactams should be those by their alkaline hydrolysis ${ }^{3,6}$ and aminolysis. ${ }^{7}$ Stehlicek et al. ${ }^{7}$ indicated that the aminolysis of the $N$-benzoyl derivatives from five- to seven-membered monocyclic lactams with $n$ butylamine proceeds exclusively through the nucleophilic attack of the amine on their exocarbonyl groups, while the aminolysis of $\mathrm{N}$ benzoyllactams having bigger rings proceeds through attack on both of exo- and endo-

carbonyl groups in tetrahydrofuran at $50^{\circ} \mathrm{C}$.

A bicyclic oxalactam, 8-oxa-6-azabicyclo[3.2.1] octan-7-one (abbreviated as BOL, 1) can be polymerized anionically under mild conditions such as room temperature in dimethyl sulfoxide (eq 1). The resulting high molecular weight polyamide (2) is easily cast to a hygroscopic membrane which has high permeability to water and high permselectivity for solutes of different size in an aqueous solution. ${ }^{8-10}$<smiles>CN1C(=O)C2COC1C2</smiles>

1

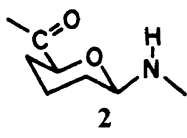

The polyamide having an acyllactam-type growable end group (3) was easily prepared by the anionic polymerization of $\mathbf{1}$ using relatively large amount of activators $\left(1.5-5 \mathrm{~mol}^{\circ} \%\right.$ to monomer) and isolated from the polymerization system. ${ }^{11}$ Novel telechelics containing amino groups and vinylbenzyl-type macromer were also obtained through the chemical modification of the acyllactam group in $3 .^{12-15}$ 


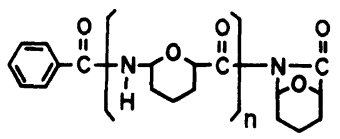

3

Therefore the polyamide is useful as a component of amphiphilic graft and block copolymers. $^{11-18}$

On the other hand, alkali metal salts of a bromo-substituted analogue, 4(e)-bromo-8-

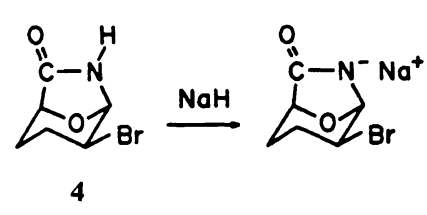

From the above-described variety of polymerizability of bicyclic oxalactams, the reactivity of their $\mathrm{N}$-acyl derivatives is expected to be different from that of the corresponding monocyclic $\mathrm{N}$-acyllactams even under similar conditions.

In the present work, the aminolysis of several acyllactams with $n$-butylamine was kinetically investigated in order to estimate and discuss the effects of the structures and the substituents on the reactivity of bicyclic $N$ acyllactams.

\section{RESULTS AND DISCUSSION}

Kinetic Analysis of the Aminolysis of $N$ Acyllactams

The reaction of $N$-benzoyllactam with $n$ butylamine through the nucleophilic attack of the amine on either exo- or endo-carbonyl groups is shown in Scheme 1. First, the aminolysis of the $N$-benzoyl derivatives of 2-pyrrolidone and BOL (BzPyrdn (6a) and BzBOL (7a), respectively) with $n$-butylamine was carried out in DMF at $25^{\circ} \mathrm{C}$ and traced by volumetric and spectroscopic analyses. While only the exo-carbonyl group was consumed in the reaction of $6 \mathbf{a}$ as reported in the litera- oxa-6-azabicyclo[3.2.1] octan-7-one (BrBOL, 4), were oligomerized in $N, N$-dimethylformamide (DMF) or dimethyl sulfoxide at $25^{\circ} \mathrm{C}$, through cleavage of the $\mathrm{C}(5)-\mathrm{O}(8)$ bond and subsequent formation of the six-membered lactam ring, accompanied by the elimination of the alkali metal bromide, to give novel oligomers (5) having a bicyclic oxalactam ring in each monomer unit in high conversion (eq 2). ${ }^{19-21}$
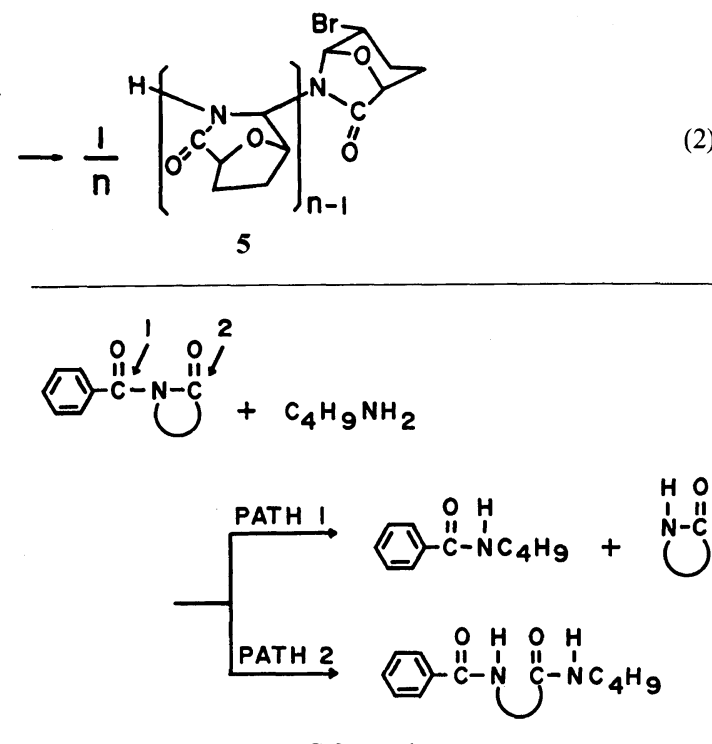

Scheme 1
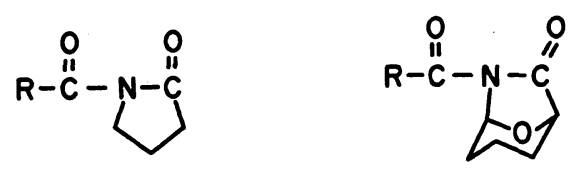
6a: $\mathrm{R}=\langle\vec{\nabla}$
7a: $R=$
6b: $\mathrm{R}=\mathrm{CH}_{3} \mathrm{CH}_{2} \mathrm{CH}_{2}-$
7b: $\mathbf{R}=\bigcup^{0} \mathrm{~J}$
7c: $\mathrm{R}=\pi \mathrm{CH}=\mathrm{CH}-$
7d: $\mathrm{R}=\mathrm{H}_{2} \mathrm{~N}-?$
7e: $\mathrm{R}=\mathrm{CH}_{3} \mathrm{O}-2$
7f: $\mathrm{R}=\mathrm{NC}-\underline{\text { U }}$
7g: $\mathrm{R}=\mathrm{O}_{2} \mathrm{~N}-\langle-\rangle$ 
ture, ${ }^{7,22,23}$ both carbonyl groups in $7 \mathrm{a}$ were found to react with the amine under the similar conditions, as shown in Figure 1. The products, $N$-butylbenzamide (8), BOL, and $N$-butyl-6benzoylaminotetrahydropyran-2-carboxamide (9), were isolated from the reaction mixture. Since no other products were found in the reaction system, the aminolysis is confirmed to be accompanied by no side reactions.

In order to estimate the reactivity of $\mathrm{N}$ benzoyllactams in detail, the data of the aminolysis of the exo-carbonyl group of $\mathbf{6 a}$ were first applied to the expression for a simple second-order reaction (Scheme 2 and eq 3 ).

$$
\left(b_{0}-a_{0}\right)^{-1} \ln \left\{a_{0}\left(b_{0}-x\right) / b_{0}\left(a_{0}-x\right)\right\}=k \cdot t
$$

where $a_{0}$ and $b_{0}$ are the initial concentrations

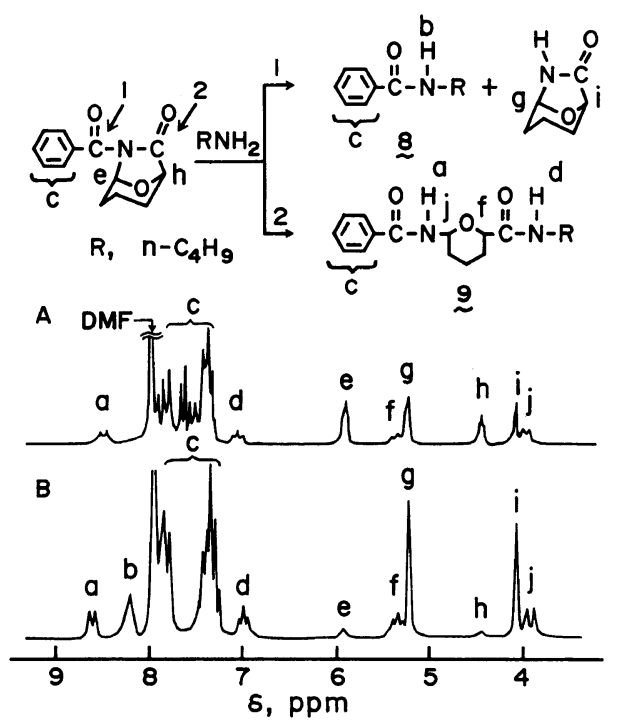

Figure 1. ${ }^{1} \mathrm{H}$ NMR spectra of reaction mixtures of $\mathrm{N}$ benzoyl-8-oxa-6-azabicyclo[3.2.1] octan-7-one (6a) with $n$-butylamine in DMF at $25^{\circ} \mathrm{C}$ (chloroform- $d_{1}$, tetramethylsilane, room temperature; $200 \mathrm{MHz}$ ). Mole ratio of $6 \mathbf{a}$ to $n$-butylamine, 0.7 . Reaction time: A, $0.4 \mathrm{~h}$; B, $5.4 \mathrm{~h}$.

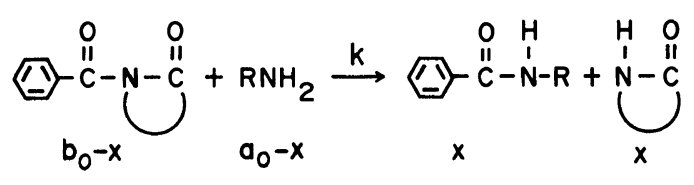

Scheme 2 of $n$-butylamine and $N$-benzoyllactam, respectively, and $x$ is the concentration of each product at time $t$. However, a certain value of the rate constant $k$, independent of the initial concentrations of the reactants in the aminolysis of 6a could not be obtained by this procedure as shown in Figure 2.

Even when the apparent rate constant was estimated at a constant initial concentration of the reactants, the logarithm of the constant was found to have no linear relationship to the reciprocal of the absolute temperature, but a maximum value at the range of $25-45^{\circ} \mathrm{C}$. In addition, the value of the reaction-order on the concentration of the amine was roughly estimated to be above 1.2 and increased with increase in concentration. These results suggest the participation of more than 2 molecules of the reactants in the rate-determining step. In

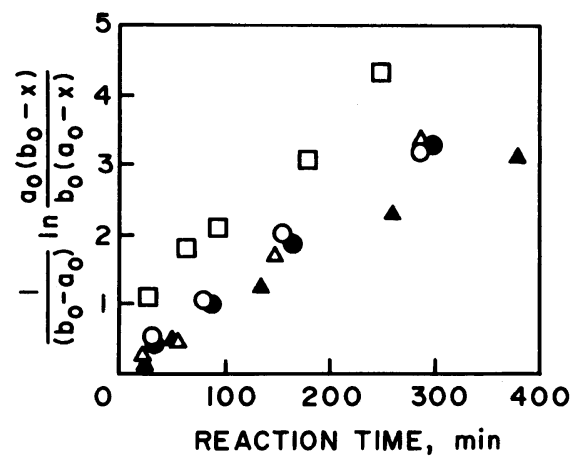

Figure 2. Kinetic analysis of aminolysis of $N$-benzoyl2-pyrrolidone with $n$-butylamine using eq 3 (DMF, $25^{\circ} \mathrm{C}$ ). Initial concentrations of $\mathrm{N}$-benzoyl-2-pyrrolidone and $n$-butylamine $\left(\mathrm{mol} \mathrm{dm}^{-3}\right): 0,0.2$ and $0.3 ; 0,0.3$ and $0.2 ; \triangle, 0.1$ and $0.3 ; \Delta, 0.3$ and $0.1 ; \square, 0.3$ and 0.6 , respectively.

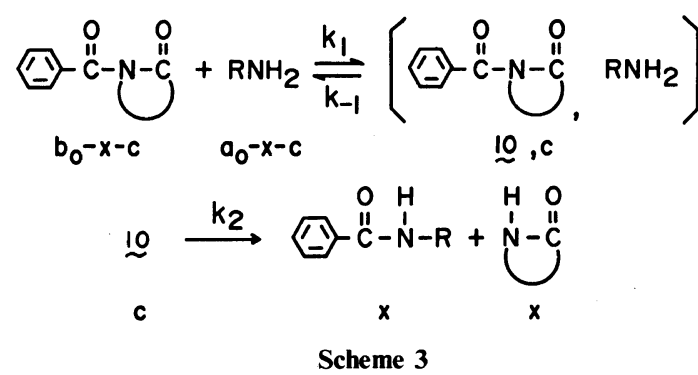


other words, the nucleophilicity of $n$ butylamine may be so weak that the attack of one molecule of the amine on the exocyclic carbonyl group in 6a does not cause the cleavage of the carbon-nitrogen bond. Therefore the present aminolysis is presumed not to be a simple second-order reaction but a complex reaction composed of several elemental reactions. $^{22}$

From the above discussion, the formation of a hypothetic intermediate (10) from the $N$ acyllactam and amine was presumed to be the rate-determining step, although the structure was ambiguous. The continuous reaction mechanism through the intermediate is expressed in Scheme 3 and eq 4 and 5.

$$
\begin{gathered}
\mathrm{d} c / \mathrm{d} t=k_{1}\left(a_{0}-x-c\right)\left(b_{0}-x-c\right) \\
-k_{-1} c-k_{2} c=0 \\
\mathrm{~d} x / \mathrm{d} t=k_{2} c
\end{gathered}
$$

where the concentration of the intermediate $(c)$ is assumed to be in a steady state. If it is much lower than both of $a_{0}$ and $b_{0}$ and the reaction constant $\left(k_{2}\right)$ for the second step is much less than the others, the following equation (eq 6) can be derived from eq 4 and 5 .

$$
\begin{aligned}
& \ln \left\{a_{0} /\left(a_{0}-x\right)\right\}+\ln \left\{b_{0} /\left(b_{0}-x\right)\right\} \\
& \quad+K^{-1}\left(b_{0}-a_{0}\right)^{-1} \ln \left\{a_{0}\left(b_{0}-x\right) / b_{0}\left(a_{0}-x\right)\right\} \\
& =k_{2} \cdot t
\end{aligned}
$$

where $K$ is $k_{1} / k_{-1}$. When $K$ is fixed at a certain value, the corresponding value of $k_{2}$ for each experimental run should be calculated from this equation. Therefore, an attempt was made to cause $K$ to converge by computer simulation to a suitable value to minimize the degree of distribution of the value of $k_{2}$. However, the value of $k_{2}$ obtained from the data in the aminolysis of $6 a$ depended still upon the initial concentrations of the reactants.

Finally, an additional activation energy was assumed needed for the scission of the carbonnitrogen bond in the acyllactam molecule which was incorporated in the intermediate $\mathbf{1 0}$
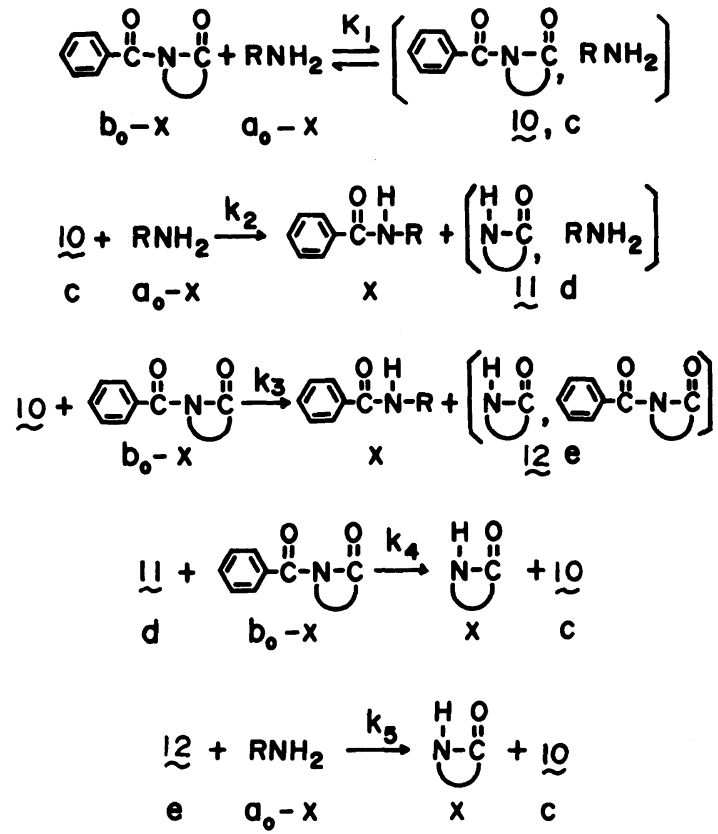

Scheme 4

under consideration. The energy may be supplied by interaction between $\mathbf{1 0}$ and another compound, although the interaction was again ambiguous. Thus, the rate-determining step was presumed to be in the reaction of the intermediate 10 with either of reactants and the following chain reaction mechanism was proposed (see Scheme 4). Since no significant interaction in another intermediates (11 and 12) defined formally in Scheme 4 are expected, they should be unstable and immediately converted into the former intermediate (10). Therefore, the formation rates of their intermediates and products should be expressed in eq $7-10$.

$$
\begin{array}{rl}
\mathrm{d} c / \mathrm{d} t= & k_{1}\left(a_{0}-x\right)\left(b_{0}-x\right)-k_{-1} c-k_{2} c\left(a_{0}-x\right) \\
& -k_{3} c\left(b_{0}-x\right)+k_{4} \mathrm{~d}\left(b_{0}-x\right) \\
& +k_{5} e\left(a_{0}-x\right)=0 \\
\mathrm{~d} d & \mathrm{~d} t=k_{2} c\left(a_{0}-x\right)-k_{4} d\left(b_{0}-x\right)=0 \\
\mathrm{~d} e / \mathrm{d} t=k_{3} c\left(b_{0}-x\right)-k_{5} e\left(a_{0}-x\right)=0 \\
\mathrm{~d} x / \mathrm{d} t=k_{2} c\left(a_{0}-x\right)+k_{3} c\left(b_{0}-x\right)
\end{array}
$$




$$
=k_{4} d\left(b_{0}-x\right)+k_{5} e\left(a_{0}-x\right)
$$

If the concentrations of the intermediates $(c, d$, and $e$ ) are assumed to be much less than $\left(a_{0}-x\right)$ and $\left(b_{0}-x\right)$ and their time-gradients to be negligible, eq 11 is derived from the aboveshown equations.

$$
\begin{aligned}
\left(a_{0}-\right. & \left.b_{0}\right)^{-2}\left[n^{-1} \ln \left\{a_{0} /\left(a_{0}-x\right)\right\}\right. \\
& +\ln \left\{b_{0} /\left(b_{0}-x\right)\right\}+\left(n^{-1}+1\right) \\
& \left.\times \ln \left\{\left(\left(a_{0}-x\right)+n\left(b_{0}-x\right)\right) /\left(a_{0}+n b_{0}\right)\right\}\right] \\
= & K_{1} k_{2} \cdot t
\end{aligned}
$$

where $n=K_{1} k_{3} / K_{1} k_{2}=k_{3} / k_{2}$.

By computer simulation using eq 11 , the value of the ratio of the rate constant $(n)$ converged to a suitable value, which minimized the degree of distribution of the value of $K_{1} k_{2}$ for each run in the aminolysis of $6 \mathbf{a}$. As shown in Figure 3, all experimental data ob-

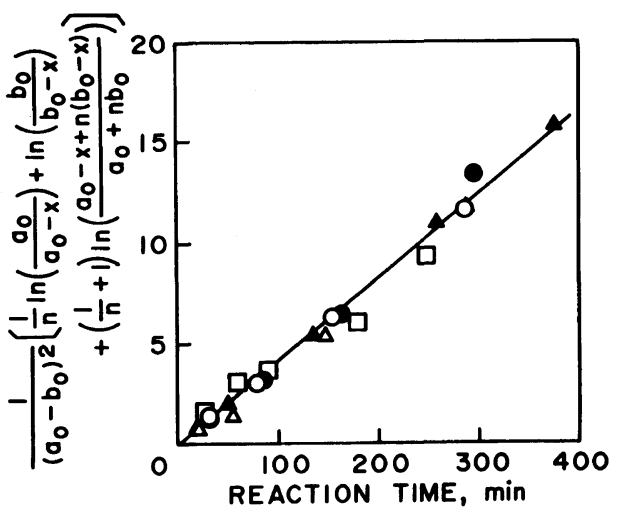

Figure 3. Kinetic analysis of aminolysis of $N$-benzoyl2-pyrrolidone with $n$-butylamine using eq 11 (DMF, $25^{\circ} \mathrm{C}$ ). Initial concentrations of $\mathrm{N}$-benzoyl-2-pyrrolidone and $n$-butylamine are the same as shown in Figure 2.

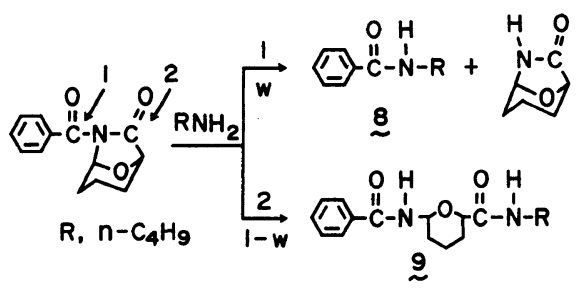

Scheme 5 tained in aminolysis in various initial concentrations of the reactants are plotted on a line with a slope of the converged values of $K_{1} k_{2}$ and $K_{1} k_{3}$.

In the aminolysis of $7 \mathbf{a}$, in which both carbonyl groups reacted with the amine (see Scheme 5), the mole fraction of the exocarbonyl group in all the reacted carbonyl groups $(w)$ was additionally defined and the exo- and endo-carbonyl aminolysis reactions are expressed as equations 12 and 13 , respectively.

$$
\begin{aligned}
& w\left(a_{0}-b_{0}\right)^{-2}\left[n^{-1} \ln \left\{a_{0} /\left(a_{0}-x\right)\right\}\right. \\
& \quad+\ln \left\{b_{0} /\left(b_{0}-x\right)\right\} \\
& +\left(n^{-1}+1\right) \ln \left\{\left(\left(a_{0}-x\right)+n\left(b_{0}-x\right)\right) /\right. \\
& \left.\left.\left(a_{0}+n b_{0}\right)\right\}\right]=K_{1} k_{2} \cdot t \\
& (1-w)\left(a_{0}-b_{0}\right)^{-2}\left[m^{-1} \ln \left\{a_{0} /\left(a_{0}-x\right)\right\}\right. \\
& \quad+\ln \left\{b_{0} /\left(b_{0}-x\right)\right\} \\
& +\left(m^{-1}+1\right) \ln \left\{\left(\left(a_{0}-x\right)+m\left(b_{0}-x\right)\right) /\right. \\
& \left.\left.\left(a_{0}+m b_{0}\right)\right\}\right]=K_{1} k_{2}{ }^{\prime} \cdot t
\end{aligned}
$$

where $n=K_{1} k_{3} / K_{1} k_{2}=k_{3} / k_{2}$ and $m=K_{1} k_{3}{ }^{\prime} /$ $K_{1} k_{2}{ }^{\prime}=K_{3}{ }^{\prime} / k_{2}{ }^{\prime}$. The constants $m, k_{2}{ }^{\prime}$, and $k_{3}{ }^{\prime}$

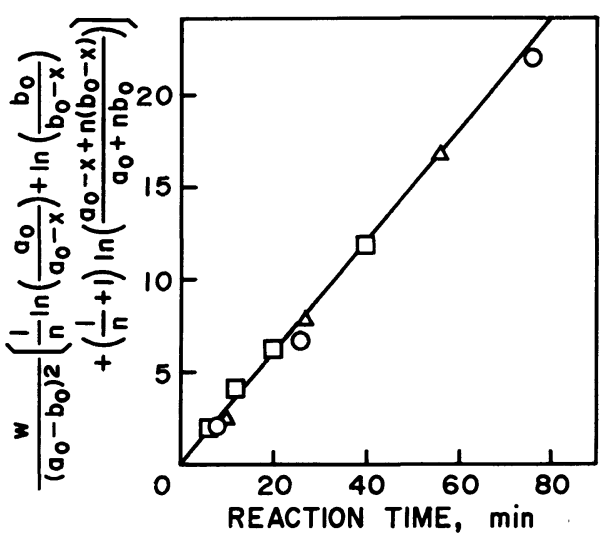

Figure 4. Kinetic analysis of the reaction of the exocyclic carbonyl group in $N$-benzoyl BOL with $n$ butylamine using eq 12 (DMF, $25^{\circ} \mathrm{C}$ ). Initial concentrations of $N$-benzoyl BOL and $n$-butylamine $\left(\mathrm{mol} \mathrm{dm}^{-3}\right.$ ): $\bigcirc, 0.1$ and $0.3 ; \triangle, 0.2$ and $0.3 ; \square, 0.06$ and 0.2 , respectively. 
for the reaction of the endo-carbonyl group correspond to those for that of the exocarbonyl group in Scheme 4, respectively.

After the value of $w$ was determined by the ${ }^{1} \mathrm{H}$ NMR spectroscopy of the products, these equations were applied to the aminolysis data of $7 \mathbf{a}$ as shown in Figures 4 and 5. The obtained values of $K_{1} k_{2}, K_{1} k_{3}, K_{1} k_{2}^{\prime}$, and $K_{1} k_{3}{ }^{\prime}$ are also suitable for all experimental data. The differences between the values of

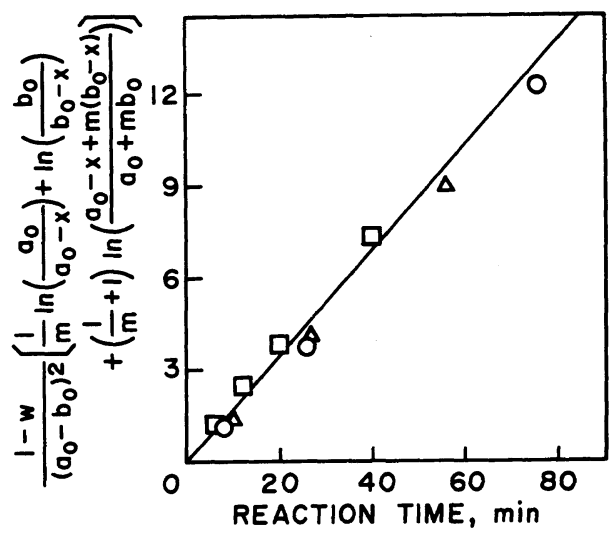

Figure 5. Kinetic analysis of the reaction of the endocyclic carbonyl group in $N$-benzoyl BOL with $n$ butylamine using eq $13\left(\mathrm{DMF}, 25^{\circ} \mathrm{C}\right)$. Initial concentrations of $N$-benzoyl BOL and $n$-butylamine are the same as shown in Figure 4.

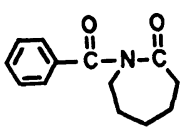

$13 a$

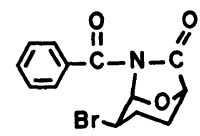

14a
$K_{1} k_{2}$ and $K_{1} k_{3}$ or $K_{1} k_{2}{ }^{\prime}$ and $K_{1} k_{3}{ }^{\prime}$, however, cannot be discussed yet, since the exact structures of the intermediates and nature of their reactions with the reactants are ambiguous. In the present work, the values of $K_{1}\left(k_{2}+k_{3}\right)$ and $K_{1}\left(k_{2}{ }^{\prime}+k_{3}{ }^{\prime}\right)$ are used as rough measure for the relative reactivity of exo- and endo-carbonyl groups, respectively, to the aminolysis of the $N$-acyllactams.

\section{Aminolysis of Several $N$-Acyllactams}

Four $N$-benzoyllactams, 6a, 7a, $N$-benzyl- $\varepsilon-$ caprolactam (BzCL, 13a), and $N$-benzoyl-4(e)bromo-8-oxa-6-azabicyclo[3-2.1]octan-7-one (BzBrBOL, 14a), reacted with $n$-butylamine in $\mathrm{DMF}$ at $25^{\circ} \mathrm{C}$. Their values of $K_{1}\left(k_{2}+k_{3}\right)$ and $K_{1}\left(k_{2}{ }^{\prime}+k_{3}{ }^{\prime}\right)$ are summarized in Table I. It is of interest that both of exo- and endo-carbonyl groups in the $N$-benzoyl derivatives of bicyclic oxalactams (7a and 14a) react with the amine, while only the exo-carbonyl group in the corresponding monocyclic $N$-benzoyllactams (6a and 13a) reacts under the present conditions. Such high reactivity of $N$-benzoyl derivatives of the bicyclic oxalactams may be attributed to the steric strain in the bicyclic skeleton. The polymerizability of bicyclic lactams having a [3.2.1]-skeleton has been discussed from the view point of their steric strain by Hall, Jr., too. $^{25}$

In Table II are summarized the bond angles of the bicyclic oxalactams and corresponding monocyclic lactams estimated from their $\mathrm{X}$ -

Table I. Relative reactivity of $N$-benzoyllactams in the aminolysis with $n$-butylamine in DMF at $25^{\circ} \mathrm{C}^{\mathrm{a}}$

\begin{tabular}{|c|c|c|c|c|c|c|}
\hline \multirow{2}{*}{$\begin{array}{l}N \text {-Benzoyl } \\
\text { lactam }\end{array}$} & \multicolumn{3}{|c|}{ Exo-carbonyl group ${ }^{b}$} & \multicolumn{3}{|c|}{ Endo-carbonyl group ${ }^{b}$} \\
\hline & $\begin{array}{l}K_{1} k_{2} \\
\times 10^{3}\end{array}$ & $\begin{array}{l}K_{1} k_{3} \\
\times 10^{3}\end{array}$ & $\begin{array}{c}K_{1}\left(k_{2}+k_{3}\right) \\
\times 10^{3}\end{array}$ & $\begin{array}{c}K_{1} k_{2}{ }^{\prime} \\
\times 10^{3}\end{array}$ & $\begin{array}{l}K_{1} k_{3}{ }^{\prime} \\
\times 10^{3}\end{array}$ & $\begin{array}{c}K_{1}\left(k_{2}{ }^{\prime}+k_{3}{ }^{\prime}\right) \\
\times 10^{3}\end{array}$ \\
\hline BzPyrdn, 6a & 0.7 & 0.3 & 1.0 & 0 & 0 & 0 \\
\hline $\mathrm{BzCL}, 13 \mathrm{a}$ & 3.9 & 2.8 & 6.7 & 0 & 0 & 0 \\
\hline $\mathrm{BzBOL}, 7 \mathrm{a}$ & 5.0 & 0.0 & 5.0 & 2.9 & 0.0 & 2.9 \\
\hline $\mathrm{BzBrBOL}, 14 \mathrm{a}$ & 80 & 110 & 190 & 32 & 76 & 108 \\
\hline
\end{tabular}

a Initial concentrations of the reactants, $0.06-0.6 \mathrm{~mol} \mathrm{dm}^{-3}$.

b $\mathrm{dm}^{6} \mathrm{~mol}^{-2} \mathrm{~s}^{-1}$ 
Aminolysis of $N$-Acyllactams

Table II. Bond angles in various lactams

\begin{tabular}{|c|c|c|c|c|}
\hline \multirow{2}{*}{ Bond angle $^{a}$} & BOL 1 & BrBOL 4 & 2-Pyrrolidone & $\varepsilon$-Caprolactam \\
\hline & degree $^{b, c}$ & degree $^{b, c}$ & degree $^{c, d}$ & degree $^{c, e}$ \\
\hline$C(2)-C(1)-C(7)$ & $109.9(3)$ & $109.5(4)$ & - & $113.6(2-3)$ \\
\hline $\mathrm{C}(2)-\mathrm{C}(1)-\mathrm{O}(8)$ & $108.8(3)$ & $107.5(4)$ & - & - \\
\hline $\mathrm{C}(7)-\mathrm{C}(1)-\mathrm{O}(8)$ & $102.4(2)$ & $102.2(4)$ & $104.7(7)$ & - \\
\hline$C(1)-C(2)-C(3)$ & $110.8(3)$ & $110.1(4)$ & - & $113.9(2-3)$ \\
\hline$C(2)-C(3)-C(4)$ & $112.3(3)$ & $110.3(4)$ & - & $114.8(2-3)$ \\
\hline$C(3)-C(4)-C(5)$ & $110.8(3)$ & $110.9(4)$ & - & $113.9(2-3)$ \\
\hline $\mathrm{C}(3)-\mathrm{C}(4)-\mathrm{Br}$ & - & $112.0(3)$ & - & - \\
\hline $\mathrm{C}(5)-\mathrm{C}(4)-\mathrm{Br}$ & - & $109.4(3)$ & - & - \\
\hline$C(4)-C(5)-N(6)$ & $112.1(3)$ & $112.7(4)$ & - & $113.7(2-3)$ \\
\hline $\mathrm{C}(4)-\mathrm{C}(5)-\mathrm{O}(8)$ & $108.6(3)$ & $105.7(4)$ & - & - \\
\hline $\mathrm{N}(6)-\mathrm{C}(5)-\mathrm{O}(8)$ & $101.3(2)$ & $102.9(4)$ & $105.8(7)$ & - \\
\hline$C(5)-N(6)-C(7)$ & $110.1(3)$ & $109.9(4)$ & $109.0(8)$ & $125.5(2-3)$ \\
\hline$C(1)-C(7)-N(6)$ & $104.8(3)$ & $105.0(4)$ & $113.2(8)$ & $118.5(2-3)$ \\
\hline $\mathrm{C}(1)-\mathrm{C}(7)-\mathrm{O}(9)$ & $126.2(3)$ & $125.7(4)$ & $124.8(9)$ & $120.6(2-3)$ \\
\hline $\mathrm{N}(6)-\mathrm{C}(7)-\mathrm{O}(9)$ & $129.0(3)$ & $129.2(4)$ & $121.9(9)$ & $120.9(2-3)$ \\
\hline$C(1)-C(8)-C(5)$ & $102.3(2)$ & $102.3(3)$ & $106.7(7)$ & - \\
\hline
\end{tabular}
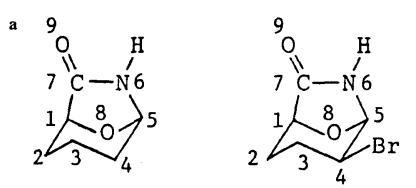

b Cited from ref 26.

c The figure in parenthesis is standard deviation.

d Cited from ref 27.

e Cited from ref 28.

ray crystallographic analysis. ${ }^{26-28}$ The table indicates that several angles in every lactam significantly differ from the ideal ones for the $s p^{2}$ and $s p^{3}$ hybrid orbitals having no strain, which should cause potential ability for ringopening. Particularly large deviation of the internal angles $(\mathrm{C} 1-\mathrm{C} 7-\mathrm{N} 6)$ in the bicyclic oxalactams must be a reflection of the abovedescribed high steric strain in the bicyclic skeleton.

The bond angles of $\mathrm{BrBOL}$ are similar with those of BOL, although the reactivity of the formor with $n$-butylamine is about forty times higher than that of the latter. This suggests the existence of an additional reason for accelerating the aminolysis reaction. For example, the dipole-dipole interaction between the carbonbromine bond and amino group, should increase the concentration of the intermediate $c$

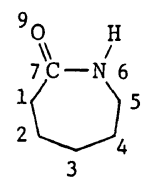

Table III. Aminolysis of various $N$-acyl derivatives of 2-pyrrolidone and $\mathrm{BOL}$ with $n$-butylamine in DMF at $25^{\circ} \mathrm{C}^{\mathrm{a}}$

\begin{tabular}{|c|c|c|}
\hline \multirow{3}{*}{$N$-Acyllactam } & $\begin{array}{l}\text { Exo-carbonyl } \\
\text { group }\end{array}$ & $\begin{array}{l}\text { Endo-carbonyl } \\
\text { group }\end{array}$ \\
\hline & $K_{1}\left(k_{2}+k_{3}\right) \times 10^{3}$ & $K_{1}\left(k_{2}^{\prime}+k_{3}^{\prime}\right) \times 10^{3}$ \\
\hline & $\mathrm{dm}^{6} \mathrm{~mol}^{-2} \mathrm{~s}^{-1}$ & $\mathrm{dm}^{6} \mathrm{~mol}^{-2} \mathrm{~s}^{-1}$ \\
\hline $6 a$ & 1.0 & 0 \\
\hline $6 b$ & 0.3 & 0 \\
\hline $7 \mathbf{a}$ & 5.0 & 2.9 \\
\hline $7 \mathbf{b}$ & 27 & 13 \\
\hline $7 c$ & 1.7 & 34 \\
\hline
\end{tabular}

a Initial concentrations of reactants, $0.04-0.60$ moldm ${ }^{-3}$.

in Scheme 4 and accelerate the aminolysis reaction.

As indicated in Table III, the reactivity of 
the exo-carbonyl group of $N$-butyryl-2pyrrolidone (6b), a model compound of the growable end group in the anionic polymerization of 2-pyrrolidone, in the aminolysis is lower than that of $\mathbf{6 a}$, whereas the reactivity of the model compound in the case of BOL, $N$ (tetrahydropyran-2-yl)carbonyl-8-oxa-6-azabicyclo[3.2.1] octan-7-one (7b), is several times higher than that of 7a. The ether group on the $\alpha$-methine adjacent to the lactam-carbonyl group seems to accelerate the reactivity of carbonyl groups in the aminolysis. The reactivity of endo-carbonyl group in $\mathrm{N}$-cinnamoyl-8-oxa-6-azabicyclo[3.2.1] octan-7-one (7c) is twenty times higher than that of the exo-carbonyl one, the reason for which is still not clarified.

As summarized in Table IV, the electronwithdrawing $p$-substituents in $N$-benzoyl $\mathrm{BOL}$ increase the reactivity of the carbonyl groups and the electron-releasing ones decrease. Therefore, the $N$-benzoyllactams having an electron-withdrawing $p$-substituent should be very effective as activators in the anionic polymerization of lactams.

The data in Table IV were applied to a Hammett equation (eq 14). ${ }^{29,30}$

$$
\log \left(k_{\mathrm{ap} \cdot \mathrm{x}} / k_{\mathrm{ap} \cdot \mathrm{H}}\right)=\rho \cdot \sigma
$$

where apparent rate constants, $k_{\mathrm{ap} \cdot \mathrm{x}}$ and $k_{\mathrm{ap} \cdot \mathrm{H}}$,

Table IV. Estimation of relative reactivity of $N$-(p-substituted benzoyl) BOL in the aminolysis with $n$-butylamine in DMF at $25^{\circ} \mathrm{C}^{\mathrm{a}}$

\begin{tabular}{|c|c|c|c|c|}
\hline \multirow{3}{*}{$\begin{array}{c}N \text {-( } p \text {-Substituted } \\
\text { benzoyl) BOL }\end{array}$} & \multirow{3}{*}{ Substituent } & \multirow{3}{*}{$\sigma^{\mathbf{b}}$} & Exo-carbonyl group & \multirow{2}{*}{$\frac{\text { Endo-carbonyl group }}{K_{1}\left(k_{2}{ }^{\prime}+k_{3}{ }^{\prime}\right) \times 10^{3}}$} \\
\hline & & & $K_{1}\left(k_{2}+k_{3}\right) \times 10^{3}$ & \\
\hline & & & $\mathrm{dm}^{6} \mathrm{~mol}^{-2} \mathrm{~s}^{-1}$ & $\mathrm{dm}^{6} \mathrm{~mol}^{-2} \mathrm{~s}^{-1}$ \\
\hline 7d & $\mathrm{H}_{2} \mathrm{~N}$ & -0.66 & 0.2 & 0.4 \\
\hline $7 e$ & $\mathrm{CH}_{3} \mathrm{O}$ & -0.27 & 2.4 & 3.3 \\
\hline $7 \mathbf{a}$ & $\mathrm{H}$ & 0 & 5.0 & 2.9 \\
\hline $7 f$ & NC & 0.66 & 102 & 108 \\
\hline $7 g$ & $\mathrm{O}_{2} \mathrm{~N}$ & 0.78 & 110 & 98 \\
\hline
\end{tabular}

a Initial concentrations of reactants, $0.02-0.3 \mathrm{~mol} \mathrm{dm}^{-3}$.

b $\sigma$-Value for the $p$-substituent of aromatic ring in the Hammett equation. ${ }^{30}$
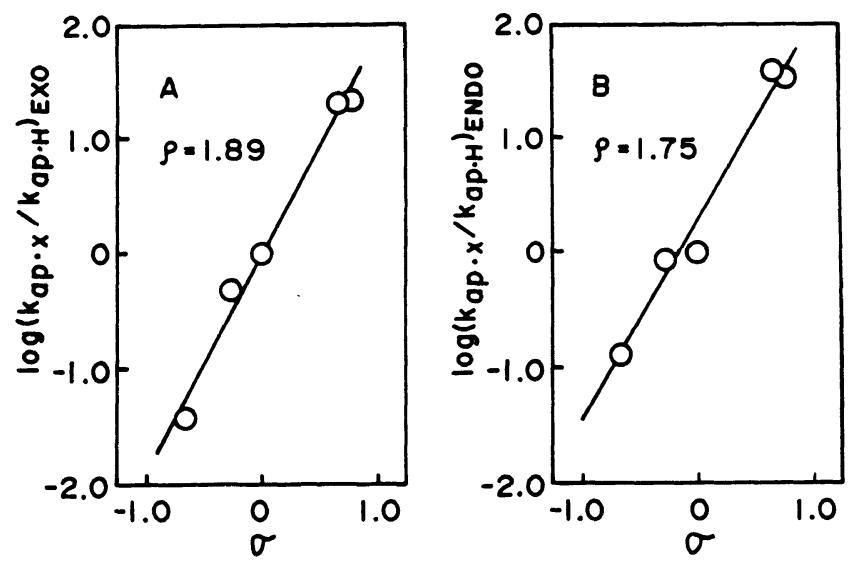

Figure 6. Application of Hammett equation to reactions of $N$-(p-substituted benzoyl) bicyclic oxalactams with $n$-butylamine in DMF at $25^{\circ} \mathrm{C}$. A, exocyclic carbonyl group; B, endocyclic carbonyl group. 
are values of $K_{1}\left(k_{2}+k_{3}\right)$ or $K_{1}\left(k_{2}^{\prime}+k^{\prime}{ }_{3}\right)$ for the $N$-benzoyl derivatives of BOL having a $p$ substituent $\mathrm{X}$ and no substituent, respectively. The substituent constant and the reaction constant are expressed by $\sigma$ and $\rho$, respectively.

As shown in Figure 6, both values of logarithms of ratios of apparent rate constants in the exo- and endo-carbonyl aminolyses are in a linear relationship with $\sigma$-values for $p$ substituents, of which coefficients of correlation are $0.99_{3}$ and $0.98_{4}$, respectively. This fact may support that the chain reaction mechanism shown in Scheme 4 is reasonable for the aminolysis reaction of $N$-acyllactams.

From the slopes of the lines in Figure 6, the corresponding $\rho$-values are estimated to $1.8_{9}$ and $1.7_{5}$, respectively. The latter is significantly bigger than the value expected from the fact that the endo-carbonyl group is farther from the $p$-substituent than the exo-carbonyl one. This may result from conjugation of $\pi$-electrons on the endo-carbonyl group with both those on the exo-carbonyl group and aromatic ring through the $\pi$-electron on the nitrogen atom, which has $s p^{2}$ hybrid orbitals.

\section{EXPERIMENTAL}

\section{$N$-Acyllactams}

In order to synthesize BzBOL (7a), $7.7 \mathrm{~g}$ $(55 \mathrm{mmol})$ of benzoyl chloride was added dropwise to a solution of $6.4 \mathrm{~g}(50 \mathrm{mmol})$ of BOL (1) in $8 \mathrm{~g}(100 \mathrm{mmol})$ of pyridine at room temperature for $1 \mathrm{~h}$. The reaction mixture was poured into $50 \mathrm{ml}$ of $0.4 \mathrm{~N}$ aqueous hydrochloric acid, and the resulting white powder (7a) was collected on a glass filter and washed with the dilute acid and water. The crude $7 \mathbf{a}$ was recovered also from the filtrate after evaporation of the solvent and extraction with chloroform. All crude 7a was recrystallized from $n$-hexane: yield $9.1 \mathrm{~g}(78 \%), \mathrm{mp} 86-87^{\circ} \mathrm{C}$ (lit. ${ }^{13,14} 88-88.5^{\circ} \mathrm{C}$ ).

The $N$-( $p$-Methoxy-, $N$-(p-cyano-, $N$ - $(p-$ nitrobenzoyl)-, $\quad N$-(tetrahydropyran-2-yl)carbonyl, and $N$-cinnamoyl derivatives of $\mathrm{BOL}$
$(7 \mathrm{e}, 7 \mathbf{f}, 7 \mathrm{~g}, 7 \mathbf{b}$, and $7 \mathrm{c}$, respectively) were prepared in pyridine by the reaction of $\mathrm{BOL}$ with the corresponding acyl chlorides. 7e; yield $68 \%$, mp $69-73^{\circ} \mathrm{C}$ (recrystallized from ethanol). Elemental analysis. Calcd for $\mathrm{C}_{14} \mathrm{H}_{15} \mathrm{NO}_{4}$ : C, $64.35 \%$; $\mathrm{H}, 5.79 \%$; N $5.36 \%$. Found: C, $64.42 \%$; H, 5.86\%; N, 5.34\%. 7f; yield $97 \%$, mp $173-177.5^{\circ} \mathrm{C}$ (from mixture of dichloromethane and $n$-hexane $(1: 2, \mathrm{v} / \mathrm{v}))$. Elemental analysis. Calcd for $\mathrm{C}_{14} \mathrm{H}_{12} \mathrm{~N}_{2} \mathrm{O}_{3}$ : C, $65.61 \% ; \mathrm{H}, 4.72 \% ; \mathrm{N}, 10.93 \%$. Found: $\mathrm{C}$, $65.41 \%$; H, $4.77 \%$; N, $10.90 \%$. 7g; yield $69 \%$, $\mathrm{mp} 161-162.5^{\circ} \mathrm{C}$ (from mixture of dichloromethane and $n$-hexane $(1: 2, \mathrm{v} / \mathrm{v}))$. Elemental analysis. Calcd for $\mathrm{C}_{13} \mathrm{H}_{12} \mathrm{~N}_{2} \mathrm{O}_{5}: \mathrm{C}, 56.52 \%$; $\mathrm{H}, 4.38 \%$; N, $10.14 \%$. Found: C, $56.65 \%$; H, $4.44 \%$; N, $10.27 \%$. 7b; yield $68 \%, \mathrm{mp} 90$ $93{ }^{\circ} \mathrm{C}$ (from $n$-hexane). Elemental analysis. Calcd for $\mathrm{C}_{12} \mathrm{H}_{17} \mathrm{NO}_{4}$ : C, $60.23 \%$; $\mathrm{H}, 7.16 \%$; $\mathrm{N}, 5.86 \%$. Found: C, $60.20 \% ; \mathrm{H}, 7.28 \%$; N, $5.95 \%$. 7c; yield $82 \%$, mp $81-84^{\circ} \mathrm{C}$ (from $n$-hexane). Elemental analysis. Calcd for $\mathrm{C}_{15} \mathrm{H}_{15} \mathrm{NO}_{3}$ : C, $70.02 \%$; $\mathrm{H}, 5.88 \%$; N $5.44 \%$. Found: C, $70.27 \%$; N, $5.92 \%$; N, $5.19 \%$. Tetrahydropyran-2-carboxylic acid was obtained quantitatively by the alkaline hydrolysis of its ethyl ester. The ester was prepared by hydrogenation of ethyl 3,4-dihydro- $2 \mathrm{H}$-pyran2-carboxylate, an intermediate for the synthesis of BOL from sodium 3,4-dihydro- $2 \mathrm{H}$ pyran-2-carboxylate, ${ }^{8,9}$ in the presence of palladium on barium sulfate in ethanol at room temperature: yield $83 \%$, bp $57-58^{\circ} \mathrm{C}$ / $1.5 \mathrm{mmHg}$. BzPyrdn (6a), $N$-butyryl-2-pyrrolidone (6b), and $\mathrm{BzCL}$ (13a) were also prepared by the similar methods, using the corresponding lactams and acid chlorides. 6a; yield $67 \%, \mathrm{mp} 90.5^{\circ} \mathrm{C}$ (lit. ${ }^{3} 85^{\circ} \mathrm{C}$ ): $6 \mathrm{~b}$, yield $57 \%$, bp $86-87.5^{\circ} \mathrm{C} / 2 \mathrm{mmHg}$ : 13a; yield $75 \%$, mp 68-69 ${ }^{\circ} \mathrm{C}\left(\right.$ lit. $\left.^{3} 67-69.5^{\circ} \mathrm{C}\right)$.

$N$-(p-Aminobenzoyl) BOL (7d) was obtained through the hydrogenation of $7 \mathrm{~g}$ catalyzed by palladium on barium sulfate in ethyl acetate at room temperature: yield $\sim 100 \%$, $\mathrm{mp} 165-167.5^{\circ} \mathrm{C}$ (from mixture of dichloromethane and $n$-hexane $(1: 2, \mathrm{v} / \mathrm{v}))$. Elemental 
analysis. Calcd for $\mathrm{C}_{13} \mathrm{H}_{14} \mathrm{~N}_{2} \mathrm{O}_{3}$ : C, $63.40 \%$; $\mathrm{H}, 5.73 \%$; N, $11.38 \%$. Found: C, $63.39 \%$; $5.82 \% ; \mathrm{N}, 11.42 \%$.

BzBrBOL (14a) was synthesized from the salt of BrBOL and benzoyl chloride in THF at $10^{\circ} \mathrm{C}$ under dry nitrogen as described in the previous paper: ${ }^{20}$ yield $36 \%$, mp $119-122^{\circ} \mathrm{C}$ (lit. ${ }^{20} 121-124^{\circ} \mathrm{C}$ ).

\section{Aminolysis of $\mathrm{N}$-Acyllactams}

To a DMF solution of $0.55 \mathrm{~g}(7.5 \mathrm{mmol})$ of $n$-butylamine in a $25 \mathrm{ml}$-volumetric flask, $0.64 \mathrm{~g}(5 \mathrm{mmol})$ of $\mathrm{BOL}$ in about $10 \mathrm{ml}$ of DMF was added with stirring in a bath controlled at $25^{\circ} \mathrm{C}$ and the flask was filled with DMF to the meniscus quickly. After each appropriate time, $1 \mathrm{ml}$ of the reaction mixture was taken out and poured into the Erlenmeyer flask to which $7 \mathrm{ml}$ of $0.05 \mathrm{~N}$ aqueous hydrochloric acid had been previously added. The consumed $n$-butylamine was determined by the volumetric titration of the excess aqueous acid with $0.05 \mathrm{~N}$ aqueous sodium hydroxide using methyl red as an indicator. The mole ratio of products obtained by the exoand endo-carbonyl aminolysis $(\mathbf{8}, \mathbf{1}$, and 9 ) was estimated from the peak intensities in the ${ }^{1} \mathrm{H}$ NMR spectrum of the reaction mixture.

Independently, 8 was prepared by the reaction of $7.0 \mathrm{~g}(50 \mathrm{mmol})$ of benzoyl chloride with $3.7 \mathrm{~g}(50 \mathrm{mmol})$ of $n$-butylamine in ether $(70 \mathrm{ml})$ in the presence of triethylamine $(5.1 \mathrm{~g}$, $50 \mathrm{mmol}$ ) at room temperature for $1 \mathrm{~h}$ : yield $4.6 \mathrm{~g}(52 \%), \mathrm{mp} 38.5-39.5^{\circ} \mathrm{C}$ (lit. $^{31} 36$ $38^{\circ} \mathrm{C}$ ). In order to synthesize 9 , the mixture of $3.6 \mathrm{~g}(30 \mathrm{mmol})$ of benzamide and $5.5 \mathrm{~g}$ (30 mmol) of $\mathrm{N}$-butyl-3,4-dihydro- $2 \mathrm{H}$-pyran2-carboxamide (15) was refluxed in benzene $(10 \mathrm{ml})$ at $80^{\circ} \mathrm{C}$ for $3 \mathrm{~h}$, using $0.5 \mathrm{~g}$ of $p$ toluene sulfonic acid monohydrate as a catalyst: yield $2.3 \mathrm{~g} \mathrm{(30 \% )}$, mp 149-151 ${ }^{\circ} \mathrm{C}$. Anal. Calcd for $\mathrm{C}_{17} \mathrm{H}_{24} \mathrm{~N}_{2} \mathrm{O}_{3}: \mathrm{C}, 67.08 \% ; \mathrm{H}, 7.95 ; \mathrm{N}$, $9.20 \%$. Found: C, 67.09\%; H, 7.91\%; N, $9.35 \%$. Compound 15 was obtained by the aminolysis of $10 \mathrm{~g}(70 \mathrm{mmol})$ of ethyl $3,4-$ dihydro- $2 H$-pyran-2-carboxylate with $20.2 \mathrm{~g}$
$(280 \mathrm{mmol})$ of $n$-butylamine at $70-80^{\circ} \mathrm{C}$ for $26 \mathrm{~h}:$ yield $9.6 \mathrm{~g}(79 \%)$, bp $110-113^{\circ} \mathrm{C} /$ $1 \mathrm{mmHg}$.

\section{Reagents}

$\mathrm{BOL}$ and $\mathrm{BrBOL}$ were prepared by the same procedure as reported earlier, ${ }^{8,9,19,20}$ and stored over phosphorus pentoxide in vacuo until use. 2-Pyrrolidone was distilled under reduced pressure after azeotropic removal of water with xylene from the 2-pyrrolidone-xylene mixture $(1: 3, \mathrm{v} / \mathrm{v}) . n$-Butylamine and pyridine were distilled after drying over pellets of sodium hydroxide. DMF was distilled over anhydrous magnesium sulfate and distilled under reduced pressure at its boiling point of less than $40^{\circ} \mathrm{C}$. Xylene, $n$-hexane, and tetrahydrofuran were distilled after refluxing over sodium metal.

\section{Instruments}

${ }^{1} \mathrm{H}$ NMR spectra were obtained with a JEOL JNM-FX-200 Fourier transform highresolution spectrometer at $200 \mathrm{MHz}$. The rate constants in the aminolysis reaction were simulated on a FACOM M382 at Nagoya University Computation Center.

\section{REFERENCES}

1. H. Sekiguchi, "Ring-Opening Polymerization," Vol. 2, K. J. Ivin and T. Saegusa Eds., Elsevier, London \& New York, 1984, Chapter 12, p 809.

2. J. Sebenda, J. Macromol. Sci. Chem., 6, 1145 (1972).

3. H. K. Hall, Jr., J. Am. Chem. Soc., 80, 6420 (1958).

4. S. Bar-Zakay, M. Levy, and D. Vofsi, J. Polym. Sci., A-1, 4, 2211 (1966).

5. S. Bar-Zakay, M. Levy, and D. Vofsi, J. Polym. Sci., $A-1,5,965$ (1967).

6. H. Sekiguchi and B. Coutin, J. Polym. Sci., Polym. Chem. Ed., 11, 1601 (1973).

7. J. Stehlicek and J. Sebenda, Collect. Czech. Chem. Commun., 45, 2524 (1980).

8. H. Sumitomo and K. Hashimoto, Macromolecules, 10, 1327 (1977).

9. K. Hashimoto and H. Sumitomo, Macromolecules, 13, 786 (1980).

10. H. Sumitomo, K. Hashimoto, and T. Ohyama, Polym. Bull., 1, 133 (1978).

11. K. Hashimoto, H. Sumitomo, and H. Shinoda, 
Polym. J., 20, 321 (1988).

12. K. Hashimoto and H. Sumitomo, Polym. J., 15, 547 (1983).

13. K. Hashimoto, H. Sumitomo, and M. Kawasumi, Polym. Bull., 11, 121 (1984).

14. K. Hashimoto, H. Sumitomo, and M. Kawasumi, Polym. J., 17, 1045 (1985).

15. K. Hashimoto and H. Sumitomo, Makromol. Chem., Suppl., 1239 (1985).

16. K. Hashimoto, H. Sumitomo, and H. Yamamori, Polym.J., 17, 679 (1985).

17. K. Hashimoto, H. Sumitomo, and H. Yamamori, Polym. J., 19, 249 (1987).

18. K. Hashimoto, H. Sumitomo, and H. Yamamori, Polym. J., 19, 1139 (1987).

19. K. Hashimoto, H. Sumitomo, and M. Suzuki, Chem. Lett., 767 (1986).

20. K. Hashimoto, H. Sumitomo, and M. Suzuki, Macromolecules, 20, 2797 (1987).

21. T. Yamane, M. Honda, T. Ashida, K. Hashimoto, and H. Sumitomo, Bull. Chem. Soc. Jpn., 60, 3911 (1987).

22. N. Ogata, K. Sanui, and K. Konishi, Koubunshi Kagaku (Japan), 30, 202 (1973).

23. J. Stehlicek and J. Sebenda, Collect. Czech. Chem. Commun., 46, 1458 (1981).

24. J. H. Espenson, "Chemical Kinetics and Reaction Mechanisms," McGraw-Hill, New York, 1981.

25. H. K. Hall, Jr., J. Am. Chem. Soc., 80, 6412 (1958).

26. Y. Gu, T. Yamane, T. Ashida, K. Hashimoto, and H. Sumitomo, Bull. Chem. Soc. Jpn., 59, 2085 (1986).

27. K. Harata, Bull. Chem. Soc. Jpn., 52, 2451 (1979).

28. F. K. Winkler and J. D. Dunitz, Acta Crystallogr., Sect. B, 31, 268 (1975).

29. L. P. Hammett, "Physical Organic Chemistry," McGraw-Hill, New York, 1970, p. 355.

30. A. Streitwieser, Jr. and C. H. Heathcock, "Introduction to Organic Chemistry," 3rd Ed, Macmillan, New York, 1985, p. 1088.

31. J. V. Braun and J. Weismantel, Ber., 55, 3165 (1922). 